\title{
Anticaries effect of dentifrices with calcium citrate and sodium trimetaphosphate
}

\begin{abstract}
Alberto Carlos Botazzo DELBEMํ, Maurício BERGAMASCHI ${ }^{2}$, Eliana RODRIGUES ${ }^{3}, \mathrm{Kikue} \mathrm{Takebayashi} \mathrm{SASSAKI}^{4}$, Ana Elisa de Mello VIEIRA ${ }^{1}$, Emilene Macario Coimbra MISSEL ${ }^{5}$
\end{abstract}

1- DDS, MS, PhD, Araçatuba Dental School, UNESP- Univ. Estadual Paulista, Araçatuba, SP, Brazil.
2- DDS, MS, PhD, Lins Dental School, Methodist University of Piracicaba, Lins, SP, Brazil.
3- DDS, PhD, Piracicaba Dental School, State University of Campinas, Piracicaba, SP, Brazil
4- PhD, Araçatuba Dental School, UNESP- Univ. Estadual Paulista, Araçatuba, SP, Brazil.
5- DDS, Graduate Student, Araçatuba Dental School, UNESP- Univ. Estadual Paulista, Araçatuba, SP, Brazil.

Corresponding address: Alberto Carlos Botazzo Delbem - Department of Pediatric Dentistry - Faculdade de Odontologia de Araçatuba - UNESP - Rua José Bonifácio, 1193 - 16015-050 - Araçatuba - São Paulo - Brasil - e-mail: adelbem@foa.unesp.br - Phone: 551836363235 - FAX: 551836363332

Received: November 26, 2009 - Modification: March 18, 2010 - Accepted: May 30, 2010

\section{ABSTRACT}

\begin{abstract}
Because of the growing concerns regarding fluoride ingestion by young children and dental fluorosis, it is necessary to develop new dentifrices. Objective: The aim of this study was to evaluate the effect of dentifrices with calcium citrate (Cacit) and sodium trimetaphosphate (TMP) on enamel demineralization. Material and Methods: Enamel blocks $(n=70)$, previously selected through surface hardness analysis, were submitted to daily treatment with dentifrices diluted in artificial saliva and to a $\mathrm{pH}$-cycling model. The fluoride concentration in dentifrices was $0,250,450,550,1,000$ and $1,100 \mu \mathrm{gg} / \mathrm{g}$. Crest $^{\mathrm{TM}}$ was used as a positive control $(1,100 \mu \mathrm{g} \mathrm{F} / \mathrm{g})$. Cacit $(0.25 \%)$ and TMP $(0.25 \%)$ were added to dentifrices with 450 and $1,000 \mu \mathrm{g} / \mathrm{g}$. Surface hardness was measured again and integrated loss of subsurface hardness and fluoride concentration in enamel were calculated. Parametric and correlation tests were used to determine difference $(p<0.05)$ and dose-response relationship between treatments. Results: The addition of Cacit and TMP did not provide a higher fluoride concentration in enamel, however it reduced $(p<0.05)$ mineral loss when compared to other dentifrices; the dentifrice with Cacit and TMP and a low fluoride concentration presented similar results when compared to a dentifrice with $1,100 \mu \mathrm{g} \mathrm{F} / \mathrm{g}(\mathrm{p}>0.05)$. Conclusions: Dentifrices with 450 and 1,000 $\mu \mathrm{g} \mathrm{F/g}$, Cacit and TMP were as effective as a gold standard one.
\end{abstract}

Key words: Dentifrices. Dental enamel. Fluorides. Calcium citrate. Tooth demineralization.

\section{INTRODUCTION}

Scientific data from the last decades confirm fluoride dentifrices provide a substantial caries protective effect against carious lesions, inhibiting demineralization and enhancing remineralization ${ }^{16}$. However, the use of fluoride dentifrices during tooth development has been considered a risk factor for dental fluorosis in children ${ }^{13}$. Based on these considerations, the use of a dentifrice with a low fluoride concentration and as effective as a gold standard one $(1,100 \mu \mathrm{g} / \mathrm{g})$ would be of great interest.

Clinical trials have been carried out to check the anticaries efficiency of low fluoride dentifrice compared to the conventional $1,100 \mu \mathrm{g} \mathrm{F} / \mathrm{g}$ dentifrice $^{2}$. Reed ${ }^{15}$ (1973) found a lower anticaries effect for a low fluoride dentifrice when compared to the conventional dentifrice. On the other hand, Winter, et al. ${ }^{21}$ (1989), Biesbrock, et al. ${ }^{3}$ (2003) and Stookey, et al. ${ }^{17}$ (2004) concluded that conventional and low fluoride dentifrices may have similar anticaries effects. A recent clinical trial ${ }^{10}$ conducted for 12 months with children aged from 2 to 4 years showed the anticaries effect of a low fluoride dentifrice was similar to the conventional fluoride dentifrice when used by caries inactive children; in children with active caries lesions the low fluoride dentifrice was less effective than the $1,100 \mu \mathrm{g} \mathrm{F} / \mathrm{g}$ dentifrice in controlling the progression of lesions.

In a recent study ${ }^{18}$, a dentifrice with low 
fluoride concentration $(500 \mu \mathrm{g} / \mathrm{g}$ ) and sodium trimetaphosphate (TMP) showed a similar effect to a standard dentifrice. The capacity of TMP to bind to crystal surfaces interferes with both dissolution and growth ${ }^{9,14}$. TMP adsorption to dental enamel increases the permselectivity facilitating the diffusion of cations into enamel ${ }^{20}$. As TMP, calcium citrate (Cacit) can also be adsorbed to hydroxyapatite (HA) and influence the surface charge distribution and precipitation of $\mathrm{HA}^{11,12}$. However, the effect of Cacit on demineralization and remineralization has not been tested yet.

The formulation of a dentifrice with a low fluoride concentration supplemented with calcium citrate and TMP could be as effective as a gold standard dentifrice and reduce fluoride ingestion by children, leading to a lower prevalence of dental fluorosis. The aim of the present study was to evaluate the effect of fluoride dentifrices with Cacit and TMP on enamel demineralization using a $\mathrm{pH}$-cycling model.

\section{MATERIAL AND METHODS}

\section{Experimental design}

Enamel blocks $(4 \times 4 \mathrm{~mm})$ were machined from bovine incisors, previously stored in $2 \%$ formaldehyde solution $\mathrm{pH} 7.0$ for 1 month, and had their surface serially polished. Baseline surface hardness measurements ( $\mathrm{SH} ; 321.0$ up to 357.0 $\mathrm{KHN}$ ) were used to eliminate blocks with anomalous properties prior to further testing. Enamel blocks were randomized (according to their mean and interval of confidence) in 7 groups of 10 and submitted to $\mathrm{pH}$ cycling ${ }^{19}$ for 5 days with treatment occurring twice a day with dentifrice slurries. The fluoride concentration in dentifrices was one of the following: $0,250,450$, $550,1,000$ and $1,100 \mu \mathrm{g} \mathrm{F} / \mathrm{g}$. Crest ${ }^{\mathrm{TM}}(1,100 \mu \mathrm{g} \mathrm{F} / \mathrm{g}$, pH 7.0, Procter \& Gamble, Cincinnati, Ohio, USA) was used as a positive control. Cacit $(0.25 \%)$ and TMP $(0.25 \%)$ were added to dentifrices with 450 and $1,000 \mu \mathrm{g} / \mathrm{g}$. After the $\mathrm{pH}$-cycling, surface and crosssectional hardness as well as fluoride concentration in enamel were analyzed.

\section{Toothpaste formulation and fluoride assessment}

The experimental dentifrices were prepared by Sara Lee Household and Body Care Research (Sara Lee Household and Body Care Research, Utrecht, The Netherlands) and had the following ingredients: carboxymethylcellulose, sodiummethyl-p-hydroxybenzoate, flavor, sodium saccharin, peppermint oil, glycerol, sorbitol, Alfa Olefin Sulphonate, hydrated silica, titanium dioxide, trisodium phosphate and water. Sodium fluoride was added to all dentifrices except for placebo. Cacit $(0.25 \%)$ and TMP $(0.25 \%)$ were added to dentifrices with 450 and $1,000 \mu \mathrm{g} \mathrm{F} / \mathrm{g}$.
Fluoride measurements of experimental dentifrices followed the technique previously described by Delbem, et al. ${ }^{6}$ (2009). After water dispersion, a sample from the suspension was treated with $2 \mathrm{~mol}$ $\mathrm{L}^{-1} \mathrm{HCl}$ for total fluoride assessment and buffered with $1 \mathrm{~mol} \mathrm{~L}^{-1} \mathrm{NaOH}$. For ionic fluoride assessment, supernatants were obtained by centrifuge (906 $\mathrm{xg} ; 20 \mathrm{~min}$ ). The same volume of TISAB II ("total ionic strength adjustment buffer", Orion, Thermo Scientific Inc., Beverly, MA, USA) was added to the solutions. Fluoride measurements were performed with an ion-selective electrode Orion 96-09 (Orion, Thermo Scientific Inc.) and an ion analyzer Orion 720 A+ (Orion, Thermo Scientific Inc.), calibrated with standards containing between 0.125 and 4.0 $\mu \mathrm{g} / \mathrm{mL}$ was used.

For total phosphorus and calcium measurements in supplemented dentifrices ( 450 and $1,000 \mu \mathrm{g} \mathrm{F} / \mathrm{g}$ ), the sample was submitted to previous acid hydrolysis adding $\mathrm{HCl} 1 \mathrm{~mol} \mathrm{~L}^{-1}$ at a temperature just below the boiling point. The total phosphorus was measured according to colorimetric determination, as described by Fiske and Subbarow ${ }^{8}$ (1925). For Ca dosage, a specific electrode (Orion 9720 BN, Thermo Scientific Inc.), attached to an ion analyzer (Orion $720 \mathrm{~A}+$ ), was previously calibrated with 5 standards, using 20 $\mu \mathrm{L}$ de ISA (ionic strength adjustor, Orion, Thermo Scientific Inc.). The ionic phosphorus and calcium were measured after a 20-min centrifugation (906 $\mathrm{x} g$ ) of the suspensions.

Toothpaste treatments and pH-cycling model

Enamel blocks $(n=70)$ were submitted individually for 5 days to a pH-cycling model at $37^{\circ} \mathrm{C}$, and remained in a fresh remineralizing solution for 2 days ${ }^{19}$. The treatment regime consisted of 1 -min soaks of all blocks ( $2 \mathrm{~mL} /$ block) of each treatment group in fresh slurries of placebo or fluoride dentifrices $\left(250,450,550,1,000,1,100 \mu \mathrm{g} \mathrm{F} / \mathrm{g}\right.$ and Crest $\left.^{\mathrm{TM}}\right)$. Dentifrices were diluted (1:3 in weight) in artificial saliva $\left(1.5 \mathrm{mmol} \mathrm{L}^{-1} \mathrm{Ca}\left(\mathrm{NO}_{3}\right)^{2} 4 \mathrm{H}_{2} \mathrm{O}, 3.0 \mathrm{mmol} \mathrm{L}^{-1}\right.$ $\mathrm{NaH}_{2} \mathrm{PO}_{4} \mathrm{H}_{2} \mathrm{O}$ and $7.5 \mathrm{mmol} \mathrm{L}^{-1} \mathrm{NaHCO}_{3}, 0.05 \mu \mathrm{g} \mathrm{F} /$ $\mathrm{mL}, \mathrm{pH} 7.0)^{4}$. The treatment was performed twice a day (before and after a demineralizing period) under agitation. The demineralizing period was 6 hours, and the solution $\left(2.2 \mathrm{~mL} / \mathrm{mm}^{2}\right)$ consisted of $2.0 \mathrm{mmol}$ $\mathrm{L}^{-1} \mathrm{Ca}\left(\mathrm{NO}_{3}\right)_{2} 4 \mathrm{H}_{2} \mathrm{O}$ and $2.0 \mathrm{mmol} \mathrm{L}-1 \mathrm{NaH}_{2} \mathrm{PO}_{4} \mathrm{H}_{2} \mathrm{O}$ in $0.075 \mathrm{~mol} \mathrm{~L}^{-1}$ acetate buffer, $0.04 \mu \mathrm{g} \mathrm{F} / \mathrm{mL}$ at pH 4.7 . The remineralizing period was set at 18 hours and the solution $\left(1.1 \mathrm{~mL} / \mathrm{mm}^{2}\right)$ consisted of $1.5 \mathrm{mmol}$ $\mathrm{L}^{-1} \mathrm{Ca}\left(\mathrm{NO}_{3}\right)^{2} 4 \mathrm{H}_{2} \mathrm{O}, 0.9 \mathrm{mmol} / \mathrm{L} \mathrm{NaH} \mathrm{PO}_{4} \mathrm{H}_{2} \mathrm{O}, 0.15$ $\mathrm{mol} \mathrm{L}^{-1} \mathrm{KCl}$ in $0.02 \mathrm{~mol} \mathrm{~L}^{-1}$ cacodylate buffer, $0.05 \mu \mathrm{g}$ $\mathrm{F} / \mathrm{mL}$ at $\mathrm{pH}$ 7.0. All blocks were rinsed before and after treatments.

\section{Hardness analysis}

After $\mathrm{pH}$-cycling, surface and cross-sectional hardness (CSH) measurements were conducted by the 
operator who was blind to treatment groups. Surface hardness of the enamel blocks was measured again $\left(\mathrm{SH}_{1}\right)$ using a Shimadzu HMV-2000 microhardness tester (Shimadzu Corporation, Kyoto, Japan) with a Knoop diamond under a $50-\mathrm{g}$ load for $10 \mathrm{~s}$. Five indentations spaced $100 \mu \mathrm{m}$ from each other and from the baseline $(\mathrm{SH})$ were made. All blocks were then longitudinally sectioned through the center of the exposed enamel. To measure cross-sectional hardness ( $\mathrm{CSH})$, half of each block was embedded in acrylic resin and the cut surfaces were exposed and polished. Three rows of 8 indentations each were made, one in the central region of the exposed dental enamel and the other two spaced $100 \mu \mathrm{m}$ from the first one, under a $25 \mathrm{-g}$ load for $10 \mathrm{~s}$. The indentations were made at 10, 30, 50, 70, 90, 110, 220 and 330 $\mu \mathrm{m}$ from the outer enamel surface. The mean values at all three measuring points at each distance from the surface were then averaged. The integrated area above the curve (cross-sectional profiles of hardness into the enamel), using the hardness values (KHN), was calculated by trapezoidal rule (GraphPad Prism, version 3.02) in each depth $(\mu \mathrm{m})$ from the lesion up to sound enamel. This value was subtracted from integrated area of sound enamel, to obtain the integrated area of the subsurface demineralized regions in enamel, which was named integrated loss of subsurface hardness $(\Delta \mathrm{KHN})^{6,18}$.

\section{Analysis of fluoride concentration in enamel}

Blocks $(4 \times 2 \mathrm{~mm})$ were obtained from one of the halves of the longitudinally sectioned blocks. An enamel biopsy was performed by immersing the enamel blocks in $0.5 \mathrm{~mol} \mathrm{~L}^{-1} \mathrm{HCl}$ for $90 \mathrm{~s}$ under agitation. The same volume of TISAB II modified with $\mathrm{NaOH}(20 \mathrm{~g} / \mathrm{L})$ was added to the solution. Fluoride measurements were performed using a fluoride specific electrode Orion 96-09 and an ion analyzer Orion $720 \mathrm{~A}+$, previously calibrated with standards containing 0.125 up to $2.0 \mu \mathrm{g} \mathrm{F} / \mathrm{mL}$ and 0.25 up to $4.0 \mu \mathrm{g} \mathrm{F} / \mathrm{mL}$.

\section{Statistical analysis}

The software GMC version $2002^{5}$ was used for the statistical analyses, and the significance limit was set at $5 \%$. Data from $\mathrm{SH}, \mathrm{SH}_{1}, \Delta \mathrm{KHN}$ and fluoride in enamel ( $\mu \mathrm{g} \mathrm{F} / \mathrm{cm}^{2}$ ) presented normal (KolmogorovSmirnov) and homogeneous (Cochran tests) distribution and were submitted to one-way analysis of variance followed by Bonferroni's test, considering the fluoride concentration in the dentifrices as fixed factor. Pearson's correlation was done to compare $\mathrm{SH} 1 \times$ Fluoride in enamel, $\triangle \mathrm{KHN} \times$ fluoride in enamel, and $\mathrm{SH}_{1} \times \Delta \mathrm{KHN}$.

\section{RESULTS}

The values (meantsd) of ionic and total fluoride concentration ( $\mu \mathrm{g} \mathrm{F/g}$ ) in the experimental dentifrice (placebo, 250, 450, 550, 1000, 1100 and positive control) were, respectively: $17.4 \pm 3.3$ and $17.2 \pm 1.4 ; 235.9 \pm 12.2$ and $235.8 \pm 9.6 ; 449.9 \pm 36.8$ and $411.9 \pm 12.8 ; 557.9 \pm 21.3$ and $558.2 \pm 5.9$; $888.4 \pm 20.9$ and $972.2 \pm 79.7 ; 1,109.6 \pm 31.4$ and $1,105.8 \pm 11.1 ; 1,115.1 \pm 71.2$ and $1,109.4 \pm 29.2$. The values (mean $\pm s d$ ) of ionic and total calcium concentration $(\mu \mathrm{g} \mathrm{Ca} / \mathrm{g})$ in the experimental dentifrice with $450 \mu \mathrm{g} \mathrm{F} / \mathrm{g}$ were $2.9 \pm 0.4$ and $115.2 \pm 2.8$ and for the dentifrice with $1,000 \mu \mathrm{g} / \mathrm{g}$ were $2.6 \pm 0.4$ and $73.3 \pm 3.6$. The values (mean $\pm s d$ ) of ionic and total phosphorus concentration $(\mu \mathrm{g} P / \mathrm{g})$ in the experimental dentifrice with $450 \mu \mathrm{g} \mathrm{F} / \mathrm{g}$ were $116.8 \pm 2.7$ and $623.9 \pm 14.7$ and for the one with $1,000 \mu \mathrm{g} \mathrm{F} / \mathrm{g}$ were $131.1 \pm 24.6$ and 551.8 46.7 .

Figure 1 shows the results of surface hardness ( $\mathrm{SH}$ and $\mathrm{SH}_{1}$ ). No statistical differences were observed among the blocks for the $\mathrm{SH}$, regardless of the treatments $(p>0.05)$. All groups showed a significant decrease in $\mathrm{SH}_{1}$ after $\mathrm{pH}$ cycling; the experimental dentifrice with $1,000 \mu \mathrm{g} / \mathrm{g}$ showed the highest value of hardness $(p<0.05)$. There was no significant difference ( $p>0.05$ ) among groups $450,1,100 \mu \mathrm{g} \mathrm{F} / \mathrm{g}$ and positive control.

Figure 2 shows the results of $\triangle \mathrm{KHN}$. No difference was observed among groups 450, 1,000, 1,100 $\mu \mathrm{g} / \mathrm{g}$ and positive control $(\mathrm{p}>0.05)$. There was a negative correlation between $\mathrm{SH}_{1}$ and $\triangle \mathrm{KHN}(r=-$ 0.933; $\mathrm{p}<0.001$ ).

Figure 3 shows the fluoride concentration in enamel after $\mathrm{pH}$-cycling. No difference was observed between group $450 \mu \mathrm{g} \mathrm{F} / \mathrm{g}$ and $550 \mu \mathrm{g} \mathrm{F} / \mathrm{g}$ ( $p>0.05)$. Although group $1,000 \mu \mathrm{g} / \mathrm{g}$ presented similar results when compared to $1,100 \mu \mathrm{g} / \mathrm{g}(\mathrm{p}>0.05)$, it was different from the positive control $(p<0.05)$. A positive correlation was observed between $\mathrm{SH}_{1}$ and

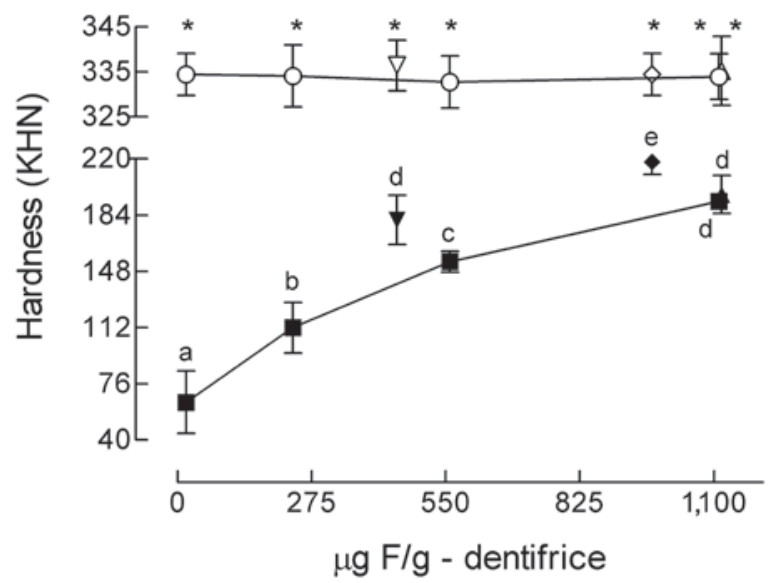

Figure 1- Surface hardness according to dentifrice. "o" indicate $\mathrm{SH}$; " $\boldsymbol{~ " ~ i n d i c a t e ~} \mathrm{SH}_{1}$; " $\triangle$ " and " $\boldsymbol{\Delta}$ " indicate $\mathrm{SH}$ and $\mathrm{SH}_{1}$ for Crest; " $\nabla$ " and " $\nabla$ " for $450 \mu \mathrm{g} \mathrm{F/g}$; " $\diamond$ " and "•" for 1,000 $\mu \mathrm{g} \mathrm{F/g} \mathrm{(mean \pm standard} \mathrm{deviation;} \mathrm{n}=10$ ). Means followed by distinct letters are statistically different (ANOVA; $p<0.05$ ); *not statistically different 


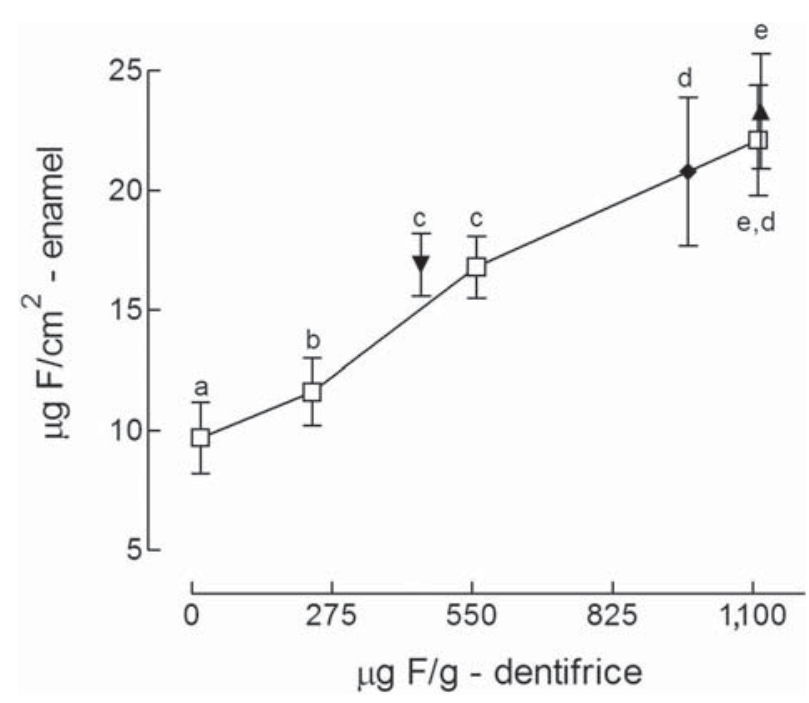

Figure 3- Fluoride concentration (mean \pm standard deviation; $n=10$ ) in enamel according to dentifrice. " $\square$ " indicate dentifrice placebo, 275, 550 and 1,100 $\mu \mathrm{g} \mathrm{F/g}$; " $\boldsymbol{\Delta}$ " indicate Crest; " $\boldsymbol{\nabla}$ " indicate $450 \mu \mathrm{g} \mathrm{F/g}$; " $1,000 \mu \mathrm{g} \mathrm{F/g}$. Distinct letters represent statistically significant differences among groups (ANOVA; $p<0.05$ )

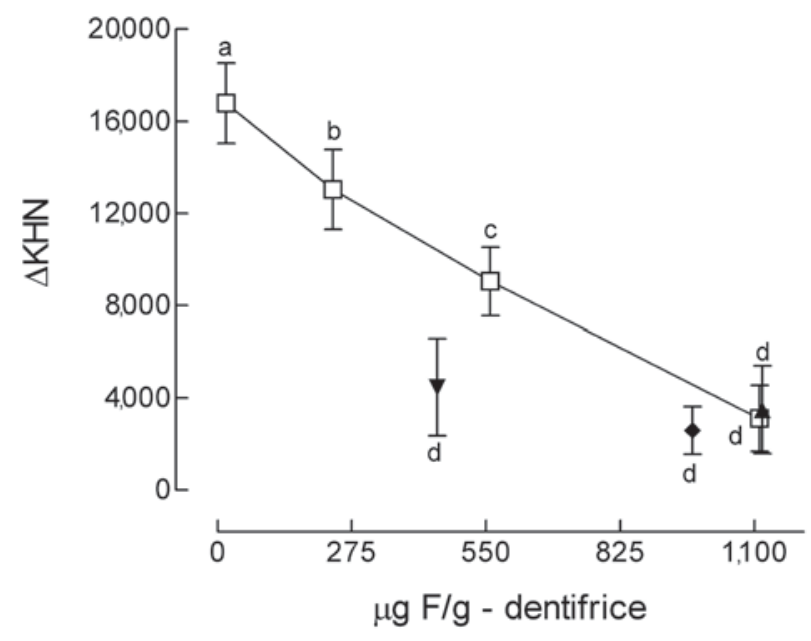

Figure 2- Values (mean \pm standard deviation; $n=10$ ) of integrated loss of subsurface hardness $(\triangle K H N)$ according to dentifrice. " $\square$ " indicate dentifrice placebo, 275, 550 and 1,100 $\mu \mathrm{g} \mathrm{F/g;} \mathrm{"} \mathbf{\Delta}$ " indicate Crest; " $\boldsymbol{\nabla}$ " $450 \mu \mathrm{g}$ F/g; " " indicate $1,000 \mu \mathrm{g} \mathrm{F/g}$. Distinct letters represent statistically significant difference among groups (ANOVA; $p<0.05$ )

fluoride in enamel $(r=0.885 ; p<0.001)$; there was a negative correlation between $\triangle K H N$ and fluoride $(r=-0.909 ; p<0.001)$.

\section{DISCUSSION}

Because of the growing concerns regarding fluoride ingestion by young children and dental fluorosis, there is a need to develop novel dentifrices with ingredients that would inhibit demineralization and enhance remineralization. This study evaluated the effect of two dentifrices supplemented with Cacit and TMP on enamel demineralization. The dentifrices were diluted in artificial saliva, aiming to supply calcium and phosphate ions to all groups to simulate what happens with human saliva ${ }^{1}$.

Since this study verified if dentifrices with Cacit and TMP would produce a synergic effect when associated to a low or a high concentration of fluoride against demineralization, the following matters were of great importance: the $\mathrm{pH}$-cycling model had to be able to differ the efficacy with the increase of fluoride concentration in the product; and any benefit from Cacit and TMP had to be detected. Dentifrices with 0 , 275, 550 e 1,100 $\mu \mathrm{g} \mathrm{F/g}$ were included in the study and a fluoride dose response was demonstrated by this methodology. The increase of fluoride concentration in enamel presented correlation with $\mathrm{SH}_{1}(r=0.885)$ and $\triangle \mathrm{KHN}(r=-0.909)$. Mineral loss was lower and a higher fluoride concentration in enamel was observed with the increase of fluoride concentration in dentifrices. The inclusion of a commercial gold standard dentifrice was important to verify the efficacy of dentifrices with Cacit and TMP.

Although dentifrices with 450 and 1,000 $\mu \mathrm{g} \mathrm{F/g}$ showed similar fluoride concentration in enamel ( $p>0.05$ ) when compared to dentifrices with 550 and $1,100 \mu \mathrm{g} \mathrm{F} / \mathrm{g}$ (Figure 3), respectively, the hardness measurements $\left(\mathrm{SH}_{1}\right.$; Figure 1$)$ of groups 450 and $550 \mu \mathrm{g} \mathrm{F} / \mathrm{g}$, and groups 1,000 and $1,100 \mu \mathrm{g} \mathrm{F} / \mathrm{g}$ were significantly different $(p<0.05)$. The results of group 450 (Cacit/TMP) of this study was similar to the group $500 \mu \mathrm{g} \mathrm{F} / \mathrm{g} 0.25 \% \mathrm{TMP}$ of the study of Takeshita, et al. ${ }^{18}$ (2009). Additionally, in this study, group $450 \mu \mathrm{g} \mathrm{F/g} \mathrm{(Cacit/TMP)} \mathrm{showed} \mathrm{a} \mathrm{lower}$ fluoride concentration in enamel and similar results of surface hardness when compared to group 1,100 $\mu \mathrm{g} / \mathrm{g}$ or to positive control (Figure 1 and Figure 3 ). As TMP presents a great affinity by ename ${ }^{20}$, it is believed that these results were promoted mainly by adsorption of TMP on the enamel surface. TMP adsorbed on enamel alters the selective permeability and the ions diffusion into the lesion cavity, mainly calcium ${ }^{21}$ or it may reduce enamel demineralization ${ }^{8,9}$. Based on surface hardness values, the ability of the dentifrice with $450 \mu \mathrm{g} \mathrm{F} / \mathrm{g}$ to inhibit demineralization was $17 \%$ better when compared to $550 \mu \mathrm{g} \mathrm{F} / \mathrm{g}$; dentifrice with $1,000 \mu \mathrm{g} / \mathrm{g}$ was only $10 \%$ better than groups $1,100 \mu \mathrm{g} \mathrm{F} / \mathrm{g}$ and positive control.

The dentifrice with $450 \mu \mathrm{g} \mathrm{F} / \mathrm{g}$ showed a similar effect with regards to lesion area (Figure 2) when compared to group $1,100 \mu \mathrm{g} \mathrm{F} / \mathrm{g}$ and positive control $(p>0.05)$, and it was better $(50 \%)$ than group $550 \mu \mathrm{g} \mathrm{F/g}(p<0.05)$. It may be assumed that TMP concentration in dentifrice was enough to inhibit hydroxyapatite demineralization showing a diminutive subsurface lesion area. In the study of 
Takeshita, et al. ${ }^{18}$ (2009), the addition of $0.25 \%$ of TMP produced similar results when compared to the $1,100 \mu \mathrm{g} \mathrm{F} / \mathrm{g}$ dentifrice. An analysis of the lesion area shows that increase of fluoride concentration from 450 to $1,000 \mu \mathrm{g} / \mathrm{g}$ in dentifrices with Cacit and TMP did not improve its efficacy when compared to groups $1,100 \mu \mathrm{g} \mathrm{F/g}$ and positive control. Cacit, TMP and fluoride have affinity by hydroxyapatite and may compete for the same sites, interfering with their mode of action. The increase in fluoride concentration may have reduced the effect of Cacit and TMP, as it is an element of greater reactivity. Another factor that may have influenced is the low solubility of Cacit, an organic salt, in water-calcium concentration in dentifrices with 450 and $1,000 \mu \mathrm{g}$ $\mathrm{F} / \mathrm{g}$ with Cacit and TMP was around 0.1 to $4.6 \%$ of the total $(2,500 \mu \mathrm{g} \mathrm{Ca} / \mathrm{g})$.

It is most likely that TMP may have assisted the diffusion of calcium ions to the inner of enamel or reduced their loss to the solutions, since dentifrice with $450 \mu \mathrm{g} \mathrm{F} / \mathrm{g}$ presented similar results of mineral loss (Figures 1 and 2 ) and different values of fluoride concentration in enamel (Figure 3) when compared to dentifrice with $1,100 \mu \mathrm{g} / \mathrm{g}$. The low availability of calcium from Cacit did not lead to better results than the ones obtained by Takeshita, et al. ${ }^{18}$ (2009) with $0.25 \%$ of TMP. There was an expectation that the increase of fluoride concentration in dentifrice $(1,100)$ associated to Cacit and TMP would result in improved values when compared to dentifrices with 450 and $1,100 \mu \mathrm{g} / \mathrm{g}$. Data from pilot studies (data not shown) have shown that TMP proportion with regards to fluoride concentration is important for an improved efficacy of the product. Thus, the concentration of $0.25 \%$ was not enough to make dentifrice with $1,000 \mu \mathrm{g} \mathrm{F} / \mathrm{g}$ better than dentifrice with $1,100 \mu \mathrm{g} \mathrm{F} / \mathrm{g}$ but it was an adequate amount to make dentifrice with $450 \mu \mathrm{g} \mathrm{F} / \mathrm{g}$ similar to dentifrice with $1,100 \mu \mathrm{g} \mathrm{F} / \mathrm{g}$.

Even knowing the limitations of this in vitro study, i.e., lack of dental biofilm and the fact that artificial saliva may present lower calcium and phosphate concentration, the experimental dentifrice may bring benefits for prevention of new lesions or as a therapy of remineralization, mainly for young children, due to fluoride ingestion and risk of fluorosis development.

\section{CONCLUSION}

Dentifrices with 450 and 1,000 $\mu \mathrm{g} \mathrm{F/g}$, Cacit and TMP were as effective as a gold standard dentifrice.

\section{ACKNOWLEDGMENTS}

The authors thank Sara Lee Household and Body Care Research (The Netherlands) for manufacturing the fluoride dentifrices.

\section{REFERENCES}

1- Amaechi BT, Higham SM. In vitro remineralisation of eroded enamel lesions by saliva. J Dent. 2001;29:371-6.

2- Ammari AB, Bloch-Zupan A, Ashley PF. Systematic review of studies comparing the anti-caries efficacy of children's toothpaste containing $600 \mathrm{ppm}$ of fluoride or less with high fluoride toothpastes of 1,000 ppm or above. Caries Res. 2003;37:85-92.

3- Biesbrock AR, Bartizek RD, Gerlach RW, Jacobs SA, Archila L. Effect of three concentrations of sodium fluoride dentifrices on clinical caries. Am J Dent. 2003;16:99-104.

4- Birkeland JM. The effect of $\mathrm{pH}$ on the interaction of fluoride and salivary ions. Caries Res. 1973;7:11-8.

5- Campos GM. GMC 2002 [online]. Ribeirão Preto: School of Dentistry; 2002 [cited 2003 Feb 21]. Available from: <http://www. forp.usp.br/restauradora/gmc/gmc.html\#gmc>.

6- Delbem ACB, Sassaki KT, Vieira AE, Rodrigues $E$, Bergamaschi $M$, Stock SR, et al. Comparison of methods for evaluating mineral loss: hardness versus synchrotron microcomputed tomography. Caries Res. 2009;43:359-65.

7- Fiske $\mathrm{CH}$, Subbarow $\mathrm{Y}$. The colorimetric determination of phosphorus. J Biol Chem. 1925;66:375-400.

8- Gonzalez M. Effect of trimetaphosphate ions on the process of mineralization. J Dent Res. 1971;50:1056-64.

9- Gonzalez M, Jeansonne BG, Feagin FF. Trimetaphosphate and fluoride actions on mineralization at the enamel-solution interface. J Dent Res. 1973;52:261-6.

10- Lima TJ, Ribeiro CCC, Tenuta LMA, Cury JA. Low-fluoride dentifrice and caries lesion control in children with different caries experience: a randomized clinical trial. Caries Res. 2008;42:46-50. 11- López-Macipe A, Gómez-Morales J, Rodríguez-Clemente R. The role of $\mathrm{pH}$ in the adsorption of citrate ions on hydroxyapatite. J Colloid Interfac Sci. 1998;200:114-20.

12- Martins MA, Santos C, Almeida MM, Costa ME. Hydroxyapatite micro- and nanoparticles: nucleation and growth mechanisms in the presence of citrate species. J Colloid Interface Sci. 2008;318:210-6. 13- Mascarenhas AK, Burt BA. Fluorosis risk from early exposure to fluoride toothpaste. Community Dent Oral Epidemiol. 1998;26:2418.

14- McGaughey C, Stowell EC. Effects of polyphosphates on the solubility and mineralization of $\mathrm{HA}$ : relevance to a rationale for anticaries activity. J Dent Res. 1977;56:579-87.

15- Reed MW. Clinical evaluation of three concentrations of sodium fluoride in dentifrices. J Am Dent Assoc. 1973;80:1401-3.

16- Rølla G, Ogaard B, Cruz RA. Clinical effect and mechanism of cariostatic action of fluoride-containing toothpastes: a review. Int Dent J. 1991;41:171-4.

17- Stookey GK, Mau MS, Isaacs RL, Gonzalez-Gierbolini C, Bartizek RD, Biesbrock AR. The relative anticaries effectiveness of three fluoride-containing dentifrices in Puerto Rico. Caries Res. 2004; 38:542-50.

18- Takeshita EM, Castro LP, Sassaki KT, Delbem AC. In vitro evaluation of dentifrice with low fluoride content supplemented with trimetaphosphate. Caries Res. 2009;43:50-6.

19- Vieira AE, Delbem AC, Sassaki KT, Rodrigues E, Cury JA, Cunha RF. Fluoride dose response in $\mathrm{pH}$-cycling models using bovine enamel. Caries Res. 2005;36:514-20.

20- Van Dijk JWE, Borggreven JM, Driessens FC. The effect of some phosphates and a phosphanate on the electrochemical properties of bovine enamel. Arch Oral Biol. 1980;25:591-5.

21- Winter GB, Holt RD, Williams BF. Clinical trial of a low-fluoride toothpaste for young children. Int Dent J. 1989;39:227-35. 